\title{
ESSENTIAL OILS FROM FOUR PIPER SPECIES
}

\author{
A. P. Martins, L. Salgueiro, ${ }^{*}$ R. Vila,$\dagger$ F. Tomi,$\$$ S. Cañigueral,$\dagger$ J. Casanova, $\$$ \\ A. Proença Da Cunha and T. Adzet†

\begin{abstract}
Lab. de Farmacognosia, Fac. de Farmácia, Universidade de Coimbra, Rua do Norte, 3000 Coimbra, Portugal; †Unitat de Farmacologia i Farmacognòsia, Fac. de Farmàcia, Universitat de Barcelona, Av. Diagonal, 643, 08028 Barcelona, Spain; \$Equipe Chimie et Biomasse, CRES-URA CNRS 2053, Université de Corse, Route des Sanguinaires, 20000 Ajaccio, France
\end{abstract}

(Received in revised form 6 April 1998)

Key Word Index-Piper capense; P. guineense; P. nigrum; P. umbellatum; Piperaceae; essential oils; GC-mass spectrometry; ${ }^{13} \mathrm{C}$ NMR.

\begin{abstract}
The essential oils from Piper capense, P. nigrum, P. guineense and P. umbellatum from S. Tomé e Príncipe were investigated for the first time. They were analysed by GC, GC-mass spectrometry and ${ }^{13} \mathrm{C}$ NMR. Monoterpene hydrocarbons were the main group of constituents in three of the samples ( $P$. capense, $P$. nigrum and $P$. umbellatum), whereas for the other species ( $P$. guineense) phenylpropanoid derivatives were the most important ones. $\beta$-Pinene $(32.5 \%)$ and $\beta$-caryophyllene $(12.6 \%)$ were the major compounds in the volatile oil of $P$. capense. Dillapiole $(44.8 \%)$, followed by myristicin $(9.8 \%)$, were the main constituents of $P$. guineense. The most important constituents in the essential oil of $P$. nigrum were limonene $(18.8 \%), \beta$-caryophyllene $(15.4 \%)$, sabinene $(16.5 \%)$ and $\beta$-pinene $(10.7 \%)$. The essential oil of $P$. umbellatum was characterised by its high $\beta$-pinene $(26.8 \%), \alpha$-pinene $(17.6 \%)$ and (E)-nerolidol $(12.4 \%)$ content. (C) 1998 Elsevier Science Ltd. All rights reserved
\end{abstract}

\section{INTRODUCTION}

The Republic of S. Tomé e Príncipe, located in West Africa's Gulf of Guinea some 180 miles off the coast of Gabon, is one of the smallest states in the world. In S. Tomé, like in many other developing countries, there is a treasure of traditional medicine and traditions concerning naturally occurring drugs, based on the empirical knowledge of medicinal and toxic plants, gained by the ancestors and passed on from generation to generation by oral tradition. During an ethnobotanical survey, it was verified that essential oil-bearing plants are widely used in this country. They are utilised in different forms, such as whole herbs, powders, extracts and vapours, for a variety of purposes.

As part of an exhaustive research of the composition of the essential oils of the aromatic and medicinal plants from S. Tomé e Príncipe, we report herein the results of the investigation of four Piper species widely used by local traditional healers, $P$. capense, $P$. guineense, $P$. nigrum and $P$. umbellatum, for which no data have been previously reported.

*Author to whom correspondence should be addressed.
The leaves of $P$. capense, known in S. Tomé as "Fiá Boba Piquina", are used as a stomachic and carminative in indigestion, flatulence and colic. It is said to cause sweating and sleepiness. The leaves of $P$. guineense, whose vernacular name is "Pó Pimenta" and, in other countries, known as "Ashanti pepper", are widely used as an antibacterial, especially to heal wounds. Its pulverised seeds are used as insecticide. The fruits of $P$. nigrum, whose vernacular name is "Pimenta", are used as a condiment and when applied externally, as a stimulant, rubefacient and disinfectant. The leaves of Piper umbellatum, known as "Fiá Boba d'Obô", are used to heal wounds and to reduce swellings and skin irritations.

The essential oils of these species were obtained by hydrodistillation of the aerial parts $(P$. capense, $P$. guineense and $P$. umbellatum) and fruits $(P$. nigrum). Qualitative and quantitative analysis of the oils were performed by GC and GC-mass spectrometry, using two fused silica capillary columns of different stationary phases, and by ${ }^{13} \mathrm{C}$ NMR. The latter has proved to be a useful technique in the investigation of the composition of essential oils [1]. On the basis of previous work [2], we have developed a technique which allows the identifi- 
Table 1. Constituents of essential oils from Piper species from S. Tomé e Príncipe

\begin{tabular}{|c|c|c|c|c|}
\hline \multirow[t]{2}{*}{ Components* } & \multicolumn{4}{|c|}{$\%$ in samples } \\
\hline & P. cap & P. guin & P. nig & P. umb \\
\hline$\alpha$-Thujene & 0.1 & 0.1 & 1.4 & 0.2 \\
\hline$\alpha$-Pinene & 8.6 & 1.1 & 5.7 & 17.6 \\
\hline Camphene & 0.2 & 0.7 & 0.1 & 0.8 \\
\hline 6-Methyl-5-hepten-2-one & - & - & - & 0.1 \\
\hline$\beta$-Pinene & 32.5 & 0.3 & 10.7 & 26.8 \\
\hline Sabinene & 0.7 & 0.1 & 16.5 & - \\
\hline Myrcene & 1.0 & 0.3 & 2.0 & 0.2 \\
\hline$\alpha$-Phellandrene & 1.8 & 8.2 & 0.7 & 0.1 \\
\hline$\alpha$-Terpinene & - & - & 0.2 & 0.2 \\
\hline$\delta$-3-Carene & 0.3 & - & 1.7 & - \\
\hline$p$-Cymene & 0.3 & 0.9 & 0.2 & 0.3 \\
\hline$(Z)$ - $\beta$-Ocimene & 0.2 & 0.1 & - & 6.8 \\
\hline Limonene & 3.6 & 2.6 & 18.8 & 3.8 \\
\hline$\beta$-Phellandrene & 2.2 & 5.9 & 2.9 & 0.6 \\
\hline$(E)$ - $\beta$-Ocimene & - & 0.1 & 0.5 & 1.4 \\
\hline$\gamma$-Terpinene & - & 0.1 & 0.4 & - \\
\hline trans-Sabinene hydrate & - & - & 0.3 & 0.1 \\
\hline 2-Nonanone & - & - & - & 0.2 \\
\hline Terpinolene & 0.2 & - & 0.4 & 0.4 \\
\hline$p$-Cymenene & - & - & - & 0.2 \\
\hline Linalool & 3.8 & 3.4 & 1.1 & 7.9 \\
\hline cis-Sabinene hydrate & 0.3 & 0.1 & 0.1 & 0.2 \\
\hline 1,3,8-p-Menthatriene & - & - & - & 0.2 \\
\hline Camphor & - & 0.8 & - & - \\
\hline Isopulegol & 0.4 & - & - & - \\
\hline Borneol & - & - & - & 0.6 \\
\hline Terpinen-4-ol & - & - & 1.7 & 0.8 \\
\hline$\alpha$-Terpineol & - & - & - & 0.5 \\
\hline$\delta$-Terpineol & - & - & 0.5 & - \\
\hline Piperitol $^{\dagger}$ & 0.3 & - & - & - \\
\hline Piperitone & 0.6 & 1.2 & - & - \\
\hline Benzenepropanoic acid, methyl ester & 0.2 & - & - & - \\
\hline Bornyl acetate & - & - & - & 0.1 \\
\hline Thymol & - & - & - & 0.1 \\
\hline Benzenepropanoic acid, ethyl ester & 7.8 & - & - & - \\
\hline$\delta$-Elemene & 0.8 & 0.1 & 1.9 & 1.0 \\
\hline$\alpha$-Cubebene & 0.2 & 0.1 & - & - \\
\hline Methyl eugenol & 0.2 & - & - & - \\
\hline$\alpha$-Copaene & 1.2 & 1.9 & 1.2 & - \\
\hline$\beta$-Elemene & - & 1.1 & 0.8 & - \\
\hline$\alpha$-Cedrene & - & - & 0.3 & - \\
\hline$\beta$-Caryophyllene & 12.6 & 1.2 & 15.1 & 9.8 \\
\hline$\alpha$-Gurjunene & 0.4 & 0.1 & 0.2 & - \\
\hline$E$ - $\beta$-Farnesene & - & 0.1 & - & 0.4 \\
\hline$\alpha$-Humulene & 1.1 & 0.5 & 1.1 & 0.7 \\
\hline allo-Aromadendrene & 0.2 & 0.1 & - & 0.2 \\
\hline Germacrene D & 3.3 & 1.5 & - & - \\
\hline$\gamma$-Muurolene & 2.1 & - & 0.5 & 0.1 \\
\hline$\beta$-Selinene & - & 0.5 & 0.7 & - \\
\hline Myristicin & 0.2 & 9.8 & - & - \\
\hline Ledene & 0.4 & 1.0 & - & - \\
\hline Zingiberene & - & - & 0.2 & - \\
\hline Furanodiene & - & - & 2.1 & - \\
\hline$(E, E)-\alpha$-Farnesene & - & - & - & 0.7 \\
\hline$\alpha$-Selinene & - & 0.8 & 0.6 & - \\
\hline$\delta$-Guaiene & - & 0.4 & - & - \\
\hline$\beta$-Bisabolene & - & - & 1.1 & - \\
\hline$\beta$-Curcumene & - & - & 0.1 & - \\
\hline Bicyclogermacrene & - & 0.6 & - & - \\
\hline$\delta$-Cadinene & 1.8 & 1.6 & 0.7 & 0.1 \\
\hline (Z)-Nerolidol & - & - & - & 0.4 \\
\hline Elemicin & - & 3.4 & - & - \\
\hline$\beta$-Elemol & 0.2 & - & 0.3 & - \\
\hline Germacrene B & - & - & 1.4 & - \\
\hline$\beta$-Caryophyllene oxide & - & - & 0.9 & - \\
\hline (E)-Nerolidol & 3.2 & 0.4 & 0.3 & 12.4 \\
\hline Germacrene D-4-ol & 0.7 & 0.2 & - & - \\
\hline (E)-2-Tridecenal & 0.4 & - & - & 0.4 \\
\hline Neryl-isovalerate & - & - & - & 0.1 \\
\hline Cubenol & 0.5 & 0.2 & - & - \\
\hline T-Cadinol & 0.3 & - & 0.3 & 0.1 \\
\hline T-Muurolol & 0.4 & - & 0.2 & 0.2 \\
\hline$\alpha$-Eudesmol & - & - & 1.2 & - \\
\hline
\end{tabular}


Table 1 (continued)

\begin{tabular}{|c|c|c|c|c|}
\hline \multirow[t]{2}{*}{ Components* } & \multicolumn{4}{|c|}{$\%$ in samples } \\
\hline & P. cap & P. guin & P. nig & P. umb \\
\hline$\alpha$-Cadinol & 0.6 & 0.2 & - & - \\
\hline$\alpha$-Elemol & - & 1.0 & - & - \\
\hline Dillapiole & - & 44.8 & - & - \\
\hline Apiole & - & 0.1 & & \\
\hline 2Z,6Z-Farnesol & 0.2 & - & - & 0.1 \\
\hline $2 E, 6 Z$-Farnesol & - & - & - & 0.1 \\
\hline $2 E, 6 E$-Farnesol & - & - & - & 0.1 \\
\hline Phytol & 0.4 & 0.2 & - & 1.0 \\
\hline Monoterpene hydrocarbons & 51.7 & 20.5 & 62.2 & 59.6 \\
\hline Oxygenated monoterpenes & 5.4 & 5.5 & 3.7 & 10.3 \\
\hline Sesquiterpene hydrocarbons & 24.1 & 11.6 & 26.2 & 13.0 \\
\hline Oxygenated sesquiterpenes & 6.1 & 2.1 & 3.2 & 13.5 \\
\hline Others & 9.2 & 58.3 & 2.1 & 1.7 \\
\hline Total identified & 96.4 & 97.9 & 97.4 & 98.2 \\
\hline
\end{tabular}

*Components are listed in order of elution on methylsilicone SE 30 column.

${ }^{\dagger}$ Specific isomer not determined.

P. cap: Piper capense; P. guin: Piper guineense; P. nig: Piper nigrum; P. umb: Piper umbellatum.

cation of the main compounds of an oil (detection limits: $0.5-1 \%$ ) by ${ }^{13} \mathrm{C} \mathrm{NMR}$, without previous fractionation. Identification is performed by computer-aided analysis of the ${ }^{13} \mathrm{C}$ NMR spectrum of the total oil, by comparing the signals obtained with those of pure compounds included in a library created in our laboratory [1]. Each compound is unambiguously identified taking into account the number of identified carbons, the number of overlapped signals and the difference of chemical shift of each resonance in the mixture spectrum and in the reference.

\section{RESULTS AND DISCUSSION}

The essential oils were obtained by hydrodistillation of the aerial parts ( $P$. capense, $P$. guineense and $P$. umbellatum) and fruits (P. nigrum). Yields were, respectively, $0.15,0.10,0.13$ and $0.26 \%$.

Results obtained for the qualitative and quantitative analysis of the essential oils are shown in Table 1. In total, 81 compounds were identified, accounting for 96.4 to $98.2 \%$ of the constituents. Three of the oils were characterised by high percentages of monoterpene hydrocarbons, but they shaved some differences in their main constituents. $\beta$-pinene $(32.5 \%)$ and $\beta$-caryophyllene $(12.6 \%)$ were the major compounds in the volatile oil of $P$. capense. The most important constituents in the oil of $P$. nigrum were limonene $(18.8 \%), \beta$-caryophyllene $(15.4 \%)$, sabinene $(16.5 \%)$ and $\beta$-pinene $(10.7 \%)$. The oil of $P$. umbellatum was characterised by its high $\beta$-pinene $(26.8 \%), \alpha$-pinene $(17,6 \%)$ and $(E)$-nerolidol $(12.4 \%)$ content. On the other hand, phenylpropanoid derivatives were the most important group of components in the oil of $P$. guineense, dillapiole $(44.8 \%)$ being the main constituent, followed by myristicin $(9.8 \%)$.

To our knowledge, this is the first time that a detailed composition of the essential oil of $P$. capense is given. A literature search and the available databases showed that the only sesquiterpene mentioned in this species, collected in Zimbabwe, is capentin, and was found in the root; this compound is not present in our sample. This is also the first time that a detailed composition of the oil of $P$. umbellatum is presented. In fact, we have found references to the leaf essential oil of this plant, collected in Brazil, but the only compounds mentioned were cadinene, caryophyllene and phellandrene [3] in unknown quantities. Despite the well known composition of the fruits of $P$. guineense [4], to our knowledge this is also the first time that the composition of the oil from the leaves of this plant is given. Most of the compounds that we have found in the leaf oil are also present in the fruit oil. The major differences found are the percentage of dillapiole $(44.8 \%$ in the leaf and $0.09 \%$ in the fruit) and the presence of safrole $(4.8 \%)$ and sarisan $(15.7 \%)$ in the fruit, compounds that we have not found in the leaf oil. The oil of $P$. nigrum fruits is well characterised and the results that we obtained are in accordance with those described previously in the literature for plants of different origins [5-7]. For example, Gopalakrishnan [7] gave the most relevant compounds of three samples that he had analysed, as $\alpha$-pinene $(5.07-6.18 \%)$, sabinene $(8.50-17.6 \%)$, $\beta$-pinene $(9.16-11.08 \%)$, myrcene $(2.20-2.30 \%)$, limonene (21.06-22.17\%), p-cymene (0.0-0.18\%), $\beta$-caryophyllene (21.59-27.70), and oxygenated constituents (3.39-5.68\%). The composition of our oil is very close to these, our values being, respectively, 5.7, 16.5, 10.7, 2.0, 18.8, 0.2, 15.1 and $6.9 \%$. Furthermore, we have found, in the oil of P. nigrum 
fruits some constituents that have not been previously quoted in the literature for this specific essential oil, for instance, furanodiene $(2.1 \%)$. This compound was identified from the ${ }^{13} \mathrm{C}$ NMR spectrum of the total essential oil and from its mass spectrum which was compared with literature data $[8,9]$.

Computer-aided analysis of essential oils using ${ }^{13} \mathrm{C}$ NMR spectroscopy has been shown to be a fast and accurate technique which can be used together with GC-mass spectrometry for unambiguous identification of some components of oils [10,11]. In this way, benzenepropanoic acid ethyl ester and germacrene D-4-ol, constituents found in the oil of $P$. capense, were also identified [12].

\section{EXPERIMENTAL}

\section{Plant material}

Aerial parts of $P$. capense L., $P$. guineense Schum. et. Thom. and $P$. umbellatum L. and fruits of $P$. nigrum L. were collected in cascata ApagaFoguinho, S. Manuel, Lagoa Amélia and Diogo Vaz, in May 1995, respectively. Species were identified and authenticated by a plant taxonomist. Voucher specimens are deposited at the Herbarium of the Instituto Botânico de Coimbra (COI) under the numbers MM 489, MM 463, MM 479 and MM 490.

Information on the medicinal uses of the species examined is based on first hand information collected by personal contact with traditional healers, usually villagers, who had knowledge of the curative property of plants. In this study, we aimed at obtaining specific information about which plants and plant parts are used, how the plant material is collected and processed to remedies and finally how the remedies are administered.

\section{Analysis of essential oils}

Essential oil contents of air-dried plant material were determined according to Ref. [13]. Analysis of volatile oils obtained by hydrodistillation was carried out by GC and GC-MS using fused silica capillary columns with two different stationary phases (Carbowax 20M and methylsilicone SE-30), as previously reported $[10,11]$. Constituents of essential oils were identified on the basis of their GC retention indices (RI) with reference to a homologous series of fatty acid Me esters, and by matching their $70 \mathrm{eV}$ mass spectra with our data and with reference libraries $[8,14]$. Most of the compounds with percentages $\geq 1.0 \%$ were also identified by ${ }^{13} \mathrm{C}$ NMR [1]. ${ }^{13} \mathrm{C}$ NMR spectra were recorded on a Bruker AC 200 Fourier Transform Spectrometer, operating at $50 \mathrm{MHz}$, equipped with a $5 \mathrm{~mm}$ probe, in $\mathrm{CDCl}_{3}$, with all shifts referred to int. TMS, with the following parameters: pulse width (PW) $3.2 \mu \mathrm{s}$, acquisition time $1.3 \mathrm{~s}$ for $32 \mathrm{~K}$ data table with spectral width (SW) of $250 \mathrm{ppm}$. The number of accumulated scans was 10000 for each sample of oil (70 $\mathrm{mg}$ in $0.5 \mathrm{ml} \mathrm{CDCl}_{3}$ ). ${ }^{13} \mathrm{C} \mathrm{NMR}$ were recorded with CDP mode-decoupling and a digital resolution of $0.763 \mathrm{~Hz} \mathrm{pt}^{-1}$. Exponential multiplication of the free induction decay with a line broading of $1 \mathrm{~Hz}$ was used before Fourier transformation.

Acknowledgements - The authors are grateful to the "Junta Nacional de Investigação Científica e Tecnológica" for financial support. We also express our gratitude to Professor Dr Jorge Paiva for his help in the identification of plant material.

\section{REFERENCES}

1. Tomi, F., Bradesi, P., Bighelli, A. and Casanova, J., Journal of Magnetic Resonance Analysis, 1995, 1, 25.

2. Formácek, V. and Kubeczka, K. H., Essential Oils Analysis by Capillary Gas Chromatography and Carbon-13 NMR Spectroscopy. John Wiley and Sons, Chichester, 1982.

3. Hammer, M. L. and Johns, E. A., Journal of Ethnopharmacology, 1993, 40(1), 53.

4. Ekundayo, O., Laakso, I., Adegbola, R. M., Oguntimein, B., Sofowora, A. and Hiltunen, R., Journal of Agricultural and Food Chemistry, 1988, 36(5), 880.

5. Lawrence, B. M., Major Tropical Spices: Pepper (Piper nigrum L.). Essential Oils 19791980. 1980, p. 141.

6. Mccarron, M., Mills, A., Whittaker, D., Kurian, T. and Verghese, J., Flavour and Fragrance Journal, 1995, 10(1), 47.

7. Gopalakrishnan, M., Menon, N., Padmakumari, K. P., Jayalekshmy, A. and Narayanan, C. S., Journal of Essential Oil Research, 1993, 5(3), 247.

8. Adams, R. P., Identification of Essential Oil Components by Gas Chromatography/Mass Spectroscopy. Allured Publishing Corporation, Carol Stream, Illinois, U.S.A., 1995.

9. Weyerstahl, P., Marschall-Weyerstahl, H., Cristiansen, C., Oguntimen, B. O. and Adeoye, A. O., Planta Medica, 1988, 55, 546.

10. Salgueiro, L., Vila, R., Tomi, F., Figueiredo, A. C., Barroso, J. G., Cañigueral, S., Casanova, J., Proença da Cunha, A. and Adzet, T., Phytochemistry, 1997, 45(2), 307.

11. Salgueiro, L., Vila, R., Tomás, X., Tomi, F., Cañigueral, S., Casanova, J., Proença da Cunha, A. and Adzet, T., Phytochemistry, 1995, 38(2), 391. 
12. Nagayama, S., Tazaki, M., Koyabashi, H. and Sumimoto, M., Phytochemistry, 1993, 33, 879.

13. Conseil de l'Europe, Pharmacopée Européene, Vol. 1. Maisonneuve S.A., Sainte Ruffine, 1983.

14. McLafferty, F. W. and Stauffer, D. B., Mass spectrometry library search system BenchTop/
$P B M$, version 3.0. Palisade Co., Newfield, NY, 1993. (Using this software the following data base was searched: McLafferty, F. W. and Stauffer, D. B., The Wiley/NBS Registry of Mass Spectral Data, 5th ed. Wiley and Sons New York, NY, 1991. 